Employee Empowerment and Organizational Citizenship Behavior ......

Basma Farahat

\title{
Employee Empowerment and Organizational Citizenship Behavior: Proactive Personality Moderating Effect
}

\section{Basma Farahat}

\section{Abstract}

This research aimed to test the relationship between employee empowerment and organizational citizenship behavior challenging dimension from the perspectives of Egyptian employees and to examine the role of proactive personality as a moderate variable. An online survey was used and data were collected from a sample of 490 respondents. Applying the structural equation modeling technique results revealed that, employee empowerment had no significant impact on changeoriented OCB. Moreover, results indicated that proactive personality has a moderating effect on the relationships between employee empowerment and change-oriented OCB.

\section{Keywords: Change-oriented OCB, employee} empowerment, proactive personality.

\section{Introduction}

Organizations should be capable of changing the attitudes and behaviors of their employees so they can look after their own morals, desires, ambitions and inclinations vicariously on a community basis (Kaur, 2011). One solution to obtain the above situation is organizational citizenship behavior (OCB).

Choi (2007) has also defined OCB as individual behavior that helps organizations to achieve its goals through affecting its social as well as psychological environmental context.

As organizations transition through change, individual discretionary contributions are crucial to success. Yet research has focused almost entirely on understanding traditional, helping, cooperating, and conforming attitudes and behaviors, such as being punctual and attending voluntary meetings. Little research has focused on positive challenging, and change-oriented discretionary behavior (Bettencourt, 2004; Choi 2007). 
Employee Empowerment and Organizational Citizenship Behavior ......

Basma Farahat

Moreover, since employees' own initiatives, ideas, suggestions, and change implementation can significantly improve the organization's functioning as well as contribute to the organizational change. It is therefore important to investigate more and find predictors of change-oriented OCB (Seppälä et al., 2012).

On the other hand, According to Days and Maharana (2016), unprecedented changes in the business environment have forced organizations to adopt effective management practices to remain competitive in the market. One of the most popular adopted management practices is employee empowerment.

In this regard, this study tries to examine the impact of employee empowerment on employees' change-oriented OCB.

Also, personality traits, specifically those that reflect a readiness to change, are progressively thought to drive the individuals' achievements and the competitive advantage of their organizations (Seibert, Crant, \& Kraimer, 2001).

As a narrowly defined personality trait, Proactive personality is intended to capture a behavioral inclination toward enacting, or changing, one's environment (Bateman \& Crant, 1993). The prototypic proactive personality is described as "one who is relatively unconstrained by situational forces, and who effects environmental change" (Bateman \& Crant, 1993).

Employees, however, vary in their response to any kind of changes and/or problems; proactive people will take action to analyze current situations or to signal possible problem areas, though more cautious employees will wait for information and sit tight for instructions to act upon (Liao, 2015). Accordingly, this provides an opportunity for research in the effect of proactive personality as a moderating variable.

This study will help expand knowledge of change-oriented OCB and employee empowerment in several ways.

First, unlike most previous studies found in the literature that have repeatedly differentiated between various OCB internal 
Employee Empowerment and Organizational Citizenship Behavior ......

Basma Farahat

dimensions, this study attends to a distinctive dimension of OCB that challenges the status quo and thus, fosters organizational change.

Second, this research will contribute to theory development by extending the traditional OCB model with empirical data from a field study on change-oriented OCB as well as add value to managers and practitioners with practical findings in an area that has rarely been investigated.

To sum up, this research is one of the first attempts to test a model centered on employee empowerment as an antecedent of change-oriented OCB as well as investigate in the role of proactive personality as a moderating variable.

\section{Literature Review}

\section{Employee Empowerment}

Employee empowerment is an organizational practice that involves offering a structure that enables employees to unleash and utilize their knowledge and skills to their fullest (Paper and Johnson, 2002).

According to Kaur, (2013) employee empowerment can be perceived as the managerial practices that are aimed at enhancing workers' responsibilities and independence, which enables them to discharge their tasks more effectively.

On the side of employees, empowerment helps in enhancing their inventiveness. When workers are empowered, they develop a feeling that they are valued by the organization and start engaging in creative thinking. Employees will try to create unique ways through creativity and innovation (Alrahamnah, 2016).

A study of Bogler and Somech (2004) focused on the relationship between teacher empowerment and organizational citizenship behavior (OCB). It examined which subscales of teacher empowerment can best predict OCB. Results revealed 
Employee Empowerment and Organizational Citizenship Behavior ......

Basma Farahat

that among six subscales of empowerment, decision making, self-efficacy, and status were significant predictors of OCB.

Another study conducted by Jha (2014) to examine the effect of psychological empowerment on organizational citizenship behavior. The sample of 319 employees of different five-star hotels formed the source of data. Findings showed that the effect of psychological empowerment on OCB has been found to be significant and positive.

To sum up, previous studies found a significant positive effect of employee empowerment on OCB. To the best of the researcher knowledge, the research at hand will be the first to propose a relationship between employee empowerment and the challenging dimension of OCB.

\section{Change-oriented OCB}

Change-oriented OCB focuses on bringing about change, not simply demonstrating cooperation and adaptability, and incorporates innovation behaviors, such as the generation and implementation of new ideas or processes (Bettencourt, 2004). The focus of change-oriented OCB is on individual discretionary behavior aimed at inducing positive change.

In a longitudinal study of 1,923 participants from a large electronics company in Korea, Choi (2007) found strong vision and innovative climate to predict change-oriented OCB.

In addition, the impact of the work environment variables on change-oriented OCB were found to be partially mediated at the individual level and fully mediated at the group level by psychological empowerment and felt responsibility for change. The results suggest that change-oriented OCB is strongly influenced by organizational level variables, even more so than group level variables.

According to Campbell (2015), there is a lucid and practical connection between performance management and change-oriented organizational citizenship behavior that affects the overall performance of any typical organization. 
Employee Empowerment and Organizational Citizenship Behavior ......

Basma Farahat

Li et al. (2016) affirm that empowered leadership has a positive impact on change-oriented OCB driven mainly by the socially embedded model. The research also explored the viability of the link between empowering leadership and changeoriented OCB to ascertain how that effect could be alleviated or even amplified. The findings of the research indicate that enabling leadership had a positive impact on the employees at the workplace which also affects change-oriented OCBs.

Kao (2017) investigated the existent relationship between change-oriented OCB and work characteristic using the work design model (knowledge-oriented approach) on immigration workers. The findings confirmed that transformational leadership had a notable positive influence on the organization climate through knowledge-oriented work characteristics.

To summarize, the development of a flexible and innovative workforce is a prerequisite for continued organizational success. In such a context, employees must regularly come up with ideas and express them to improve existing methods, procedures, and policies (Bettencourt, 2004). For this reason, challenging forms of OCB are becoming a critical component of employee performance (Morrison \& Phelps, 1999).

\section{Proactive Personality}

Proactive personality is defined as a relatively stable tendency to effect environmental changes. Individuals with a prototypical proactive personality take action to influence their environments, or "identify opportunities and act on them, show initiative, take action, and persevere until meaningful change occurs". Proactive individuals show willingness and determination to pursue a course of action, characteristics that are central to models of self-development (Bertolino, Truxillo, and Fraccaroli, 2011).

The workplace is not static because the business environment is on a consistent change trajectory that forces 
Basma Farahat

employees to interact with new scenarios on a frequent basis. Individuals who possess the proactive personality trait have a unique advantage over other employees in that it allows them to see more to do thus allowing them to be productive. Such individuals are likely to identify the limits of their required responsibilities but will cover the proverbial "extra mile" to ensure their efforts are at optimal levels as compared to individuals who lack the personality trait (Bergeron, Schroeder \& Martinez, 2014).

Moreover, proactive personality was also tested in previous studies as a moderator. For example, the study of Samad (2007) examined the contribution of social structural characteristics on employee empowerment and whether proactive personality plays a role in moderating the above stated relationship among managers in Malaysia. Hierarchical regression analyses of 584 responses revealed that proactive personality was found to be a moderator to the relationship between social structural characteristics and employee empowerment.

To sum up, Proactive personality individual does not react to the current developments, as most individuals would; instead, they come up with innovative solutions to developments using foresight. Ultimately, a proactive personality is likely to contribute positively to the performance rating of the employees and the business organization as a whole. 


\section{Research Model and Hypothesis}

\section{Figure (1) Research Model}

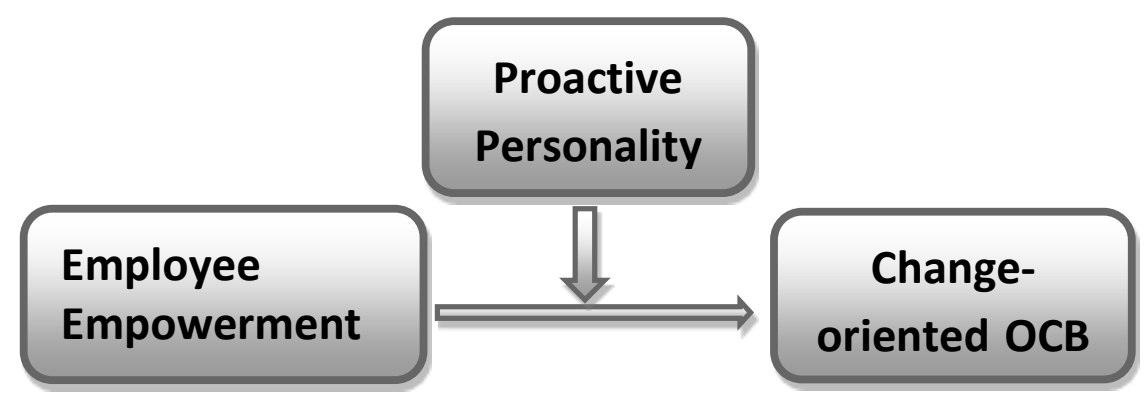

H1: Employee empowerment has a significant influence on change-oriented OCB.

H2: Proactive personality moderates the relationship between employee empowerment and change-oriented OCB such that, the relationship is stronger when proactive personality is high rather than low.

\section{Research Methodology}

The online survey method used for collecting data for analysis, where personally-administered questionnaire is adopted from earlier studies.

The population for this research consists of all Egyptians employees work in different organizations. Those Egyptians form the sample under study and the sample size is 490 .

Along with descriptive statistics and other statistical techniques, the structural equation modeling (SEM) will be used to test the hypothesized model.

\section{Research Results}

Table (1)

\begin{tabular}{|l||l||l||c||c|}
\hline \multicolumn{4}{|c|}{ Structural Path } & Coefficient \\
\hline H1 & $\begin{array}{l}\text { Employee } \\
\text { empowerment }\end{array}$ & $\rightarrow$ & $\begin{array}{l}\text { Change- } \\
\text { Oriented OCB }\end{array}$ & $.118^{\mathrm{ns}}$ \\
\hline
\end{tabular}

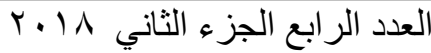

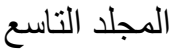


Employee Empowerment and Organizational Citizenship Behavior ......

Basma Farahat

According to the result shown in table (1), hypothesis 1 is not supported where; employee empowerment has no significant effect on change-oriented OCB $(\beta=.118, \mathrm{~ns})$.

Table (2)

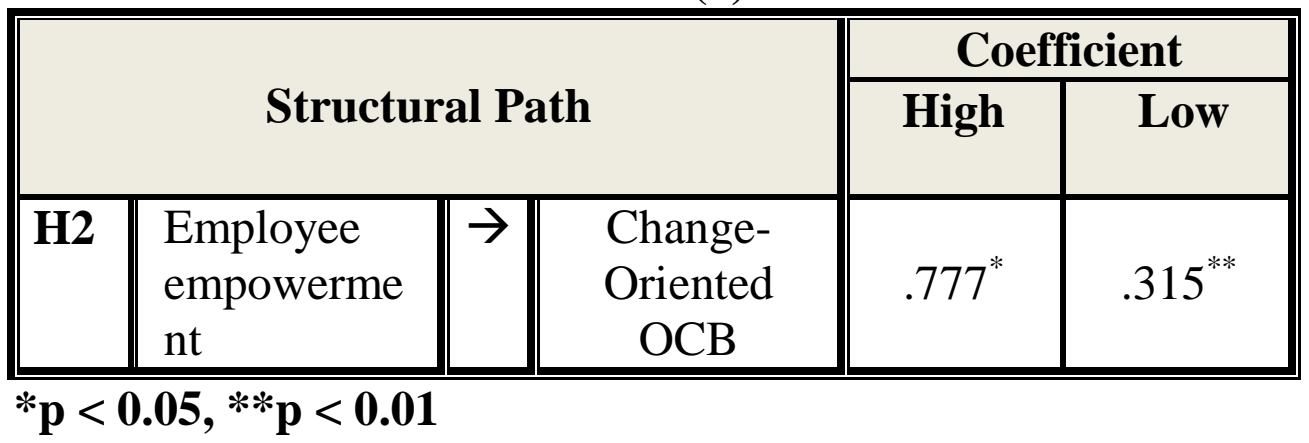

Results in the above table (2) revealed that $\mathrm{H} 2$ is accepted where; the effect of employee empowerment on change-oriented OCB is stronger for those with high proactive personality $(\beta=.777$, $\mathrm{p}<0.05)$ than for those with low proactive personality $(\beta=.315, \mathrm{p}<$ $0.01)$.

\section{Research Implications}

Whether the organization strives for change in its different manners and to minimize the resistance against it, it is then recommended to undertake the administrative functions pertaining employee empowerment towards those who have a proactive personality and striving for change as well as introducing suggestions and implement work functions in novel and innovative manners. When those employees are empowered and allowed sufficient power and room to partake in decisionmaking as well as using the organization's resources, their change-oriented behaviour will in turn increase and boost the organization's performance. This also extends to the organization's ability to confront the constant changes in the business worl 
Employee Empowerment and Organizational Citizenship Behavior ......

Basma Farahat

\section{References}

- Alrahamnah, B. A. (2016). The Impact of Empowerment in Enhancing Creativity among Employees: An Empirical Investigation. International Journal of Academic Research in Business and Social Sciences, 6(3), 160-165.

- Bateman, T. S., \& Crant, J. M. (1993). The proactive Component of Organizational Behavior: A Measure and Correlates. Journal of Organizational Behavior, 14 (2), 103-118.

- Bergeron, D. M., Schroeder, T. D., \& Martinez, H. A. (2014). Proactive personality at work: seeing more to do and doing more?. Journal of Business and Psychology, 29(1), 71-86.

- Bertolino, M., Truxillo, D., \& Fraccaroli, F. (2011). Age as moderator of the relationship of proactive personality with training motivation, perceived career development from training, and training behavioral intentions. Journal of Organizational Behavior, 32, 248-263.

- Bettencourt, L. A. (2004). Change-Oriented Organizational Citizenship Behaviors: The Direct And Moderating Influence Of Goal Orientation. Journal of Retailing, 80(3), 165-180.

- Bogler, R., \& Somech, A. (2004). Influence of teacher empowerment on teachers' organizational commitment, professional commitment and organizational citizenship behavior in schools. Teaching and Teacher Education, 20, 277-289.

- Campbell, J. W. (2015). Identification and performance management: An assessment of change-oriented behavior in public organizations. Public personnel management, 44(1), 46-69.

- Choi, J. N. (2007). Change-oriented organizational citizenship behavior: effects of work environment characteristics and intervening psychological processes. Journal of Organizational Behavior: The International Journal of Industrial, Occupational and Organizational Psychology and Behavior, 28(4), 467-484.

- Days, S., \& Maharana, T.R. (2016). Employee Empowerment and Organisational Effectiveness: A Conceptual Framework. Training \& Development Journal, 7(2), 106-107.

- Jha, S. (2014). Transformational leadership and psychological empowerment. South Asian Journal of Global Business Research, 3 (1), $18-35$.

- Kao, R. H. (2017). The relationship between work characteristics and change-oriented organizational citizenship behavior: A multi-level study 
Employee Empowerment and Organizational Citizenship Behavior ......

Basma Farahat

on transformational leadership and organizational climate in immigration workers. Personnel review, 46(8), 1890-1914.

- Kaur, G. (2013). Employee Empowerment and Organizational Effectiveness: A Comparative Study of Public, Private and Foreign Banks in Some North Indian States. PhD thesis. Retrieved from http://dspace.thapar.edu:8080/jspui/handle/10266/2786

- Kaur, P. (2011). Organizational Citizenship Behavior: Changing Employees into Citizens. International Journal of Management and Business Studies, 1 (4), 87-89.

- Li, M., Liu, W., Han, Y., \& Zhang, P. (2016). Linking empowering leadership and change-oriented organizational citizenship behavior: The role of thriving at work and autonomy orientation. Journal of Organizational Change Management, 29(5), 732-750.

- Liao, P.Y. (2015). The Role of Self-Concept in the Mechanism Linking Proactive Personality to Employee Work Outcomes. Applied Psychology, 64(2), 421-443.

- Morrison, E. W. \& Phelps C. C. (1999). Taking charge at work: Extrarole efforts to initiate workplace change. The Academy of Management Journal, 42(4), 403-419.

- Paper, D.J., \& Johnson, J.J. (2002). A Theoretical Framework Linking Creativity, Empowerment, and Organizational Memory. Creativity and Innovation Management, 6(1), 32-44.

- Samad, S. (2007). Social Structural Characteristics and Employee Empowerment: The Role of Proactive Personality. International Review of Business Research Papers, 3 (4), 254-264.

- Seibert, S. E., Kraimer, M. L., \&Crant, J. M. (2001). What do proactive people do? A longitudinal model linking proactive personality and career success. Personnel psychology, 54(4), 845-874.

- Seppälä, T., Lipponen, J., Bardi, A., \&Pirttilä-Backman, A. M. (2012). Change-oriented organizational citizenship behaviour: An interactive product of openness to change values, work unit identification, and sense of power. Journal of Occupational and Organizational Psychology, 85(1), 136-155. 